\title{
Network Dynamics and Cluster Evolution: Changing Trajectories of the Aluminium Extrusion Industry in Dali, China
}

\author{
Peng-Fei Li, Harald Bathelt \& Jici Wang
}

\begin{abstract}
Version Post-print/accepted manuscript
Citation Li, P. F., Bathelt, H., \& Wang, J. (2012). Network dynamics and cluster (published version) evolution: Changing trajectories of the aluminium extrusion industry in Dali, China. Journal of Economic Geography, 12(1), 127-155.
\end{abstract}

Copyright / License

Publisher's Statement

This is a pre-copyedited, author-produced PDF of an article accepted for publication in Journal of Economic Geography following peer review. The version of record [Li, P. F., Bathelt, H., \& Wang, J. (2012). Network dynamics and cluster evolution: Changing trajectories of the aluminium extrusion industry in Dali, China. Journal of Economic Geography, 12(1), 127-155.] is available online at: http://joeg.oxfordjournals.org/content/12/1/127 [doi: $10.1093 /$ jeg/lbr024].

How to cite TSpace items

Always cite the published version, so the author(s) will receive recognition through services that track citation counts, e.g. Scopus. If you need to cite the page number of the TSpace version (original manuscript or accepted manuscript) because you cannot access the published version, then cite the TSpace version in addition to the published version using the permanent URI (handle) found on the record page. 
April 18, 2011

Word count: ca. 11,00o (main text)

\title{
Network Dynamics and Cluster Evolution:
}

\section{Changing Trajectories of the Aluminium Extrusion Industry in Dali, China}

\author{
by \\ Peng-Fei Li \\ University of Toronto, Department of Political Science, \\ Sidney Smith Hall, 100 St. George Street, Toronto ON M5S 3G3, Canada; \\ and Peking University, Department of Urban and Economic Geography, \\ 5 Yiheyuan Road, Beijing 100871, P.R. China; \\ E-mail: mrlipengfei@gmail.com \\ Harald Bathelt \\ University of Toronto, Department of Political Science and \\ Department of Geography \& Program in Planning, Sidney Smith Hall, 100 St. George \\ Street, Toronto ON M5S 3G3, Canada; E-mail: harald.bathelt@utoronto.ca, URL: \\ http://www.harald-bathelt.com
}

Jici Wang

Peking University, Department of Urban and Economic Geography, 5 Yiheyuan Road, Beijing 100871, P.R. China;

E-Mail:wjc@pku.edu.cn

Paper to be re-submitted to J ournal of Economic Geography 


\title{
Network Dynamics and Cluster Evolution: Changing Trajectories of the Aluminium Extrusion Industry in Dali, China
}

\begin{abstract}
Research on industrial clusters has shifted in a paradigmatic way from an exploration of structural ideal-types toward evolutionary explanations. Thus far, however, networks - the key concept in the former paradigm - and evolution - the focus in the latter - remain somewhat unconnected in the literature. This article addresses this gap by developing a comprehensive tri-polar analytical framework of cluster evolution. This framework combines the three concepts of context, network and action, allowing each to evolve in interaction with the others. The empirical analysis applies this framework to the aluminium extrusion industry cluster in Dali, Guangdong province, which has developed over a period of 30 years. Our study finds that with the formation of a new generation of entrepreneurs, previous kinship-based learning networks have disappeared, causing significant changes to action and interaction within and between firms.
\end{abstract}

Keywords. Network erosion, cluster evolution, entrepreneurial generational change, aluminium extrusion industry

J EL Codes. D83, L26, R11 


\section{Introduction: Divergence of Two Paradigms}

The concepts of network and evolution are key in the discussions of industrial clusters that have developed in two successive stages. First, academic interest was attracted by the robust growth of certain industrial districts, clusters or regional innovation systems (Brusco, 1982; Piore and Sabel, 1984; Porter, 1990; Cooke and Morgan, 1994; Saxenian, 1994). Despite the different approaches that were used, a consensus about the structure of such competitive regions was that they combine economic activities and culture at the local level through untraded (aside from traded) linkages, echoing with the social-embeddedness argument in economic sociology (Granovetter, 1985). This "network paradigm" suggested that networks of local agents, which are often associated with mutual trust, provide a third way of governing economic relations beyond the dual structure of market and hierarchy. They generate regional prototypes of tacit knowledge that is successfully shared and where new knowledge is created (Malmberg and Maskell, 2002). Second, due to changes in regional configurations, such as the Third Italy (Whitford, 2001; Hadjimichalis, 2006), Silicon Valley (Saxenian and Hsu, 2001) and Hollywood (Scott and Pope, 2007), a transition has taken place from a static to a more evolutionary view of clusters (Wang, 2010). This has given rise to a new "evolutionary paradigm" that focuses on dynamic changes, drawing inspirations from concepts such as path dependency, lock-in and industry-life cycles (Frenken et al., 2007; Boschma and Iammarino, 2009; Martin, 2010; MacKinnon et al., 2010). Until now, however, the two dimensions, network and evolution, have remained somewhat unconnected in the literature on industrial clusters.

In our reading, two different perspectives of cluster theory are more or less implicitly used under different circumstances. On the one hand, when looking back to explain successful regions, a social-cultural-institutional perspective stands out that emphasizes the impact of local routines and traditions on interactive learning and 
innovative activities. On other occasions, a second perspective treats clusters as static economic entities without adaptive capabilities and reflective rationalities. In this view, cluster firms are forced to take strategies of relocation and/or internationalisation under the pressure of competition from developing countries (Amighini and Rabellotti, 2006; Sammarra and Belussi, 2006; Chiarvesio et al., 2010). Both views, to some extent, neglect broader levels of change in social networks and local culture and their impacts on cluster evolution. This paper argues that a close linkage between network dynamics and cluster evolution needs to be established to develop a coherent conceptualisation of clusters as an analytical framework for cluster studies. Without changes in networks and conventions, regional renaissance would barely be a "flash in the pan", induced by temporary increases in demand. Signs of recovery, however, may not lead to a succession of the evolutionary path or life cycle of a cluster. Without an evolutionary perspective, regional success would be determined by the existing local manufacturing culture (Saxenian, 1994; Gertler, 2004), which would also provide only a partial understanding.

The goal of this article is to connect the two paradigms in cluster research by formulating a tri-polar framework for the analysis of cluster dynamics. Following the call for dynamic cluster theorisation (Martin, 2010) through evolutionary thinking and cluster-life cycles - but constructed in a different way - we suggest a broad analytical framework enabling a contextualised theoretical exploration. The tri-polar framework suggested in this paper builds on the three pillars of context, network and action, and integrates them in an organic way at the local level. By contextualising social networks, we introduce the possibility of network dynamics and, hence, emphasize varied effects of networks on local agency over time. In other words, contextualised networks help explain and understand deeper transformations of clusters. Furthermore, by placing networks in dynamic context-action configurations, we indicate how new cluster paths can be created through collective mobilisation of local agents. In the empirical analysis, 
we investigate the trajectories of the aluminium extrusion industry cluster in Dali, a "small town" in Guangdong province, over a period of 30 years. We demonstrate how the evolution of this cluster can be analysed using the tri-polar framework. As such, this article addresses Yeung and Lin's (2003) call for theories and conceptualisations that are developed from within Asian economic geographies.

Our article is structured as follows: Section 2 summarises the two strands of conceptualisations of cluster dynamics: evolutionary approaches and cluster-life cycles, and emphasizes the need to integrate network dynamics in cluster evolution. From this, a tri-polar analytical framework is developed in Section 3, and the pillars of this framework and their interrelations are explained. After a brief overview of the research methods and data used in Section 4, Section 5 focuses on the formation of Dali's aluminium extrusion industry, emphasizing the context of China's transitional economy and the existence of traditional social relations. Section 6 investigates the evolution of this cluster and illustrates how local social networks have eroded with a shift in the cluster's context and the formation of a new generation of entrepreneurs. Moreover, it shows how actions and interactions within and between firms have been shaped by changes in contexts and networks. Section 7 summarises our arguments and draws conclusions.

\section{Conceptualisations of Cluster Dynamics: Regional Path Dependence and Cluster-Life Cycles}

The growing interest in cluster dynamics, in part, originates from the underconceptualisation of previous ideal-type structural models in explaining crises and

\footnotetext{
${ }^{1}$ This refers to a lower-level administrative unit, rather than a small economy. In China, many clusters are manifested at lower administrative levels, such as "counties" or "towns", yet the size of these economies and their population are large (Wang, 2001). Dali, a "town" of 32 villages, had a total population of 500,000 people in 2009, including 240,000 "guest or immigrant workers" from other Chinese regions. Economically, Dali is a city, but a "small town" in administrative terms.
} 
structural changes of clusters. Although every cluster is unique, early studies of innovative regions tried to reveal decisive common characteristics, such as the importance of small and medium-sized enterprises, competition-vs.-cooperation relationships among enterprises, and local cultures of entrepreneurship and joint trust (Becattini, 1990; Camagni, 1991; Saxenian, 1994). Policy implications from these findings are easy to formulate but, at the same time, hard to implement since localised benefits are expected to happen only after clusters have been formed. The important question of how cluster structures emerge in the first place has often been neglected or viewed as a process that is "individualistic" in nature (Krugman, 1993). Since factors that support a cluster's genesis may differ from those that support its ongoing growth (Bresnahan et al., 2001; Henn, 2006), a systematic understanding of clusters requires a dynamic framework.

One strand of the literature on cluster dynamics centres on the concepts of path dependence and lock-in related to evolutionary theories. A conceptual challenge when applying metaphors from evolutionary economics or evolutionary biology to economic geography is to justify the transferability of path-dependence explanations - originating from micro-level analyses of organisational behaviour - to the aggregate local/regional level (Penrose, 1952). A natural way of justifying the use of evolutionary ideas at the local level is to demonstrate that geography matters in the realisation of path-dependent processes. Such processes - be it related to technological lock-ins, externalities or institutional inertia - do not occur in a spaceless world. The idea that a firm's interactive-learning processes, strategic choices and organisational routines are shaped by local cultures and institutional environments has been repeatedly pointed out in the network tradition of cluster research and in studies related to the institutional turn in regional development (Amin, 1999). In this view, path dependence is associated with a place-dependent evolutionary process (Martin and Sunley, 2006). Various empirical 
studies add to this argument by illustrating that regional path dependence can persist over a very long time period (Grabher, 1993; Saxenian, 1994, 2006; Rigby and Essletzbichler, 1997).

Further theoretical exploration of evolutionary thinking in economic geography goes beyond the claims of regional stability. History matters, but does not determine future trajectories of clusters (Bathelt and Glückler, 2011). Related to this, it appears that path dependence over-accentuates the continuity and stability of regional developments while discontinuities and structural crises, which are equally if not more important, are usually not conceptualised (Bathelt, 2009). By analysing new industries or technologies triggered by external shocks, the canonical path-dependence model reveals a contradiction in that path dependence matters once a new path has emerged; but it seemingly plays no role in the early stages of evolution (Martin, 2010). Consequently, to understand and conceptualise new path formation in a consistent manner requires a reinterpretation of and different perspective on clusters.

In the traditional path-dependence model, clusters tend to be treated as homogenous entities that form the unit of analysis. Even though social relations of firms are often acknowledged in the localisation process of paths, the central focus is the overall intensity of local networks, rather than their internal structure, let alone changes in the network structure of social relations. Since the position in a network impacts the kind of knowledge an agent can receive, a diversified set of agents is likely associated with diversified structures of local knowledge flows and networks. Therefore, new path creation of clusters - an outcome driven by interaction between a diversified set of agents - is more likely to occur in regions with varied structures (Frenken et al., 2007; Boschma and Iammarino, 2009). The focus on the heterogeneous and diverse nature of regions revitalises evolutionary thinking in economic geography. In focusing on the relations of local agents in a national transformation context, it has been demonstrated 
that re-bundling processes in a region without diversified networks may lead to the development of hollow, instead of renewed clusters (Bathelt, 2009). By viewing regions as composite systems and drawing inspirations from new evolutionary ideas in political science, Martin (2010) puts forward an alternative model of path dependence to highlight dynamic path processes. By inspecting interactions of agents in different network positions, Sydow et al. (2010) make an effort to combine conceptions of path dependence with Giddens' (1984) structuration theory, thus trying to disentangle the underlying agency processes of new path creation in clusters. Our tri-polar framework, developed in the next section, draws from a similar conceptualisation.

Although contributions to new path creation complement the previous interpretation of clusters as quasi-permanent structures, evolutionary conceptualisations of cluster dynamics, thus far, have a relatively narrow focus of analysis, such as industry, technology or institutional structures. Aspects of the co-evolution of interrelated economic, technological, institutional and socio-cultural arenas remain underconceptualised, yet need to become "a key issue for further research" (Martin and Sunley, 2006, 413). Furthermore, MacKinnon et al. (2010) criticize evolutionary approaches as neglecting social structure, labour relations and capital accumulation at a broader macro level.

Another strand of conceptualisations of cluster dynamics draws on industry- or product-life cycle theories (Vernon, 1966; Abernathy and Utterback, 1978; Klepper, 1997). The essence of life-cycle theories is to describe industry dynamics associated with technological and market changes. Different from Vernon's (1966) use of life cycles in the discussion of international shifts in trade and the location of industries, geographical applications in regional context are mainly focused on dynamic shifts of industries within a specific cluster. Life-cycle theories suggest that with the maturation of industries, product design and dominant knowledge become stable and codified over 
time. Since the communication of tacit knowledge and technological innovation are key features of innovative clusters, a natural corollary of life-cycle theories is that such clusters most likely develop in an early rather than a mature stage of industrial development (Staber, 1997; Iammarino and McCann, 2006). The point of this argument is that the evolution of clusters corresponds with and follows from the technological paradigm of those industries that form their bases.

Cluster-life cycles, in this view, are a regional version of industry-life cycles. The strong emphasis on the role of technology in cluster dynamics, however, adds some element of determinism to these explanations. When using technological paradigms to explain the rise or failure of industrial clusters (Kenney and von Burg, 1999), there is a danger of a-posteriori reasoning (Saxenian, 1999). It is easy to explain technological changes of an industry when looking back, but difficult to foretell what will happen in the future. Only after clusters succeed or fail can the rationality of a technology regime be fully understood. In practice, however, a change in technology is not an external factor that determines the cluster's evolution, but the outcome of the interconnected nature of the firms' choices and actions along the dynamics of cluster development. Industry- and product-life cycle theories tend to predict technological change, rather than explaining the origins of technologies resulting, for instance, from cluster innovations. ${ }^{2}$

Although evolutionary and life-cycle conceptualisations of cluster dynamics draw from different origins, they are both relatively weak in integrating changes of networks and culture in their theoretical construction. In cluster-life cycles, different stages are mainly distinguished by observable indicators, such as firm size and number of

\footnotetext{
${ }^{2}$ Other conceptualisations of cluster-life cycles differ in that they presume that such cycles are existent, rather than constructed. Related research pays attention to uncovering the characteristic forces at each stage of a cluster-life cycle (Pouder and St. John, 1996; Swan, 2002; Maskell and Malmberg, 2007; Menzel and Fornahl, 2009). Early discussions of this type of cycles imply that clusters experience a unidirectional stage-to-stage development. To free clusters from such deterministic reasoning, Menzel and Fornahl (2009) add feedback loops allowing clusters to jump back to earlier stages during the later stages of clusters. Such relaxation of stage rigidity does not, however, fully eliminate the mechanical characteristics of cluster-life cycles.
} 
employees, or by indicators that are less easily measurable, such as technology and diversity of local knowledge pools. In terms of the institutional dimension applied in evolutionary economic geography, it is institutional inertia rather than reforms of institutions that are captured by lock-in processes. Local business culture and social networks, which have been extensively discussed in the network paradigm of clusters, seem to be deliberately excluded in theoretical frameworks of cluster dynamics.

Although prior empirical observations already pointed out the changes of local networks, recent work has made an effort to integrate findings of network dynamics with cluster evolution. For example, Nadvi (1999) finds that the dominance of family networks has decreased in a surgical instrument cluster in Pakistan, due to the engagement in global markets, and illustrates changes in the influence of social linkages on the local production system. Owen-Smith and Powell (2006) trace the expansion processes of local networks in two biotechnology clusters investigating the effects of different network dynamics on local learning processes. Turner (2010), in turn, emphasizes the importance and relational nature of interfirm networks in the development of the English wine industry. In another study, Ter Wal and Boschma (2011) include different intensities of network structure in various stages of the cluster-life cycle, but do not provide an explanation of why networks would change.

An important question that yet remains to be solved is how networks and culture can be integrated into a dynamic cluster framework in a coherent manner. In line with the above studies that combine network dynamics and cluster evolution, we develop a framework that conceptualises the relationships of those forces enabling and shaping diverse trajectories of clusters. Based on observations of the agents' behaviour at the local level, as well as beyond, this conceptualisation aims to extract key influences of cluster dynamics in the long run. Instead of asking how clusters will evolve, our analytical framework gives priority to the question of why clusters change. This does not 
presume the existence of a general theory that extracts the critical forces behind the dynamics of clusters since the relational analytical framework below is both deductive and inductive. It draws from empirical research and is open to comparison and revision based on other empirical cases. 3 The next section formulates our analytical framework of cluster evolution.

\section{Network Dynamics and Cluster Evolution: Towards an Analytical Framework}

Any conceptualisation of clusters presumes an interpretation of what a cluster is. In our view, a cluster is neither an organism, which can grow or decline per se, nor an entity, which can be described by a single rationality or technology. In our context, a cluster is a group of agents and firms that are bound together geographically, technologically and relationally. In this vein, trajectories of clusters are aggregate outcomes of the individual choices and actions of local agents, as well as of the synergies that derive from them. ${ }^{4}$ The analytical framework of cluster dynamics is thus formulated in relation to the individual and collective actions and motivations of local agents. From the contingent, relational and accumulated characteristics of the local agent's behaviours (Bathelt and Glückler, 2011), we identify three important pillars as central analytical categories in our framework. These are context, network and action (see, also, Hayter, 2004), bound together in a reflexive manner that stimulates an evolutionary dynamic (Figure 1).

\footnotetext{
${ }^{3}$ Feldman et al.'s (2005) model of entrepreneurs, in a similar way, develops a conceptualisation based on the development of the biotechnology and ICT industries.

${ }^{4}$ Sometimes trajectories of clusters are unanticipated outcomes of the agents' purposive actions because some external contexts are beyond the control of local agents (Merton, 1936). This will be further explored below.
} 
Figure 1 about here

$* * * * * * * * * * * * * * * * * * * * * * * * * * *$

Context. Actions of local agents are contingent, which makes it hard to predict such actions. Contingency is directly related to the first pillar of our framework: the specific context in which actors are situated (Bathelt and Glückler, 2003). By context, we mean the economic and institutional structures influencing local actors in the process of making and fulfilling decisions. This influence also includes the results of previous actions of other agents. The economic structure of clusters includes more than industry characteristics. It entails market conditions, technological patterns, intra-firm organisation and the dominant interfirm linkages inside and beyond the region. Since we define context from an agent perspective, the economic structure of clusters becomes especially manifest when it is internalised by local agents impacting their strategic actions. To interpret the dynamic nature of the economic context and make appropriate decisions is not a routine process, even for market leaders. It becomes an intrinsic part of business thinking for the local agents to systematically monitor and be curious about potential changes in their environment.

The institutional structure, in turn, refers to the local and non-local political regimes, routines, conventions, norms and value and belief systems that implicitly but profoundly affect mutual trust and potential interaction between cluster agents. Some aspects of local conventions and culture may be more closely related to cluster evolution, such as entrepreneurship spirit, while others may be less relevant. Since individual economic agents also live in the region, local institutional and business structures are closely interrelated with one another. Both the economic and institutional context may exhibit numerous elements in different areas. The economic and institutional settings, which are structured by the division of labour and the geographical distance between 
activities (Storper, 2009a), influence the local actors' knowledge base and their interaction. When applied to cluster evolution, the economic and institutional dimensions of context are sometimes blurred since long-term interfirm connections can form powerful interest groups, stabilising the local institutional context (Grabher, 1993).

Context both constrains and enables action in clusters. From a psychological and pragmatic perspective, Storper (2009b, 13) proposes an informational interpretation of context, the structural component of which "is defined by the division of labour in which the actor finds himself, which has a decisive influence on the information environment for the individual, hence his 'input' structure of cues and reference points”. In this sense, context has an impact on the ways how actors find and apply information and knowledge, leading them to choose certain actions over others. The relationship between context and action is neither pre-determined nor normative. A specific context does not determine what actors do, but affects and may limit ways of coordinating actions in a given situation. In other words, there are different frameworks of action in possible worlds of production, yet, in a certain context, some coordinated collective actions are more likely than others (Storper and Salais, 1997). The effects of context on performance are not predetermined as they can be positive or negative (Storper, 2009a). On the negative side, the practical environment of actions restricts what kind of knowledge local actors may receive. On the positive side, context enables what agents in clusters can do, by creating a bias towards certain kinds of knowledge. Therefore, for local agents the question is not how to escape restricted contexts and/or enter more beneficial environments, but how to reflexively interpret practical situations and make appropriate adjustments. It thus leads to certain forms of collective and individual action. Context becomes an important influence once it has been internalised into the actors' motivations and behaviour. In sum, the constitution of context represents the duality of structure, both as a medium and an outcome of the agents' practices (Giddens, 1984). 
From a structural perspective, actions are structured by contexts. At a particular time for a specific local actor, context is a given constraint. Over a longer time span, however, contexts are constructed by actions and are thus variable. Routines and conventions of doing business are formed based on foreseeable expectations about the mutual behaviour of others as an outcome of recursive interaction. Ongoing interfirm relations are consolidated through the success of every single transaction. Competitive patterns of industries are shaped by the choices and practices of actors in comparison with those of their competitors. Context is thus not a pre-destined background against which agents make choices and take actions; rather, it is constructed and sustained by ongoing practices of all agents. This means that the context, in which all agents are situated, usually cannot be controlled by single or exclusively local agents. At the cluster level, actors can influence their context in several ways, but there are also important components that are out of the hands of local agents. Although firms in clusters may engage in collective action to alter the supply conditions of a specific industry, they cannot easily change the demand of customers or influence national macroeconomic policies, legislative frameworks and education systems.

Network. Network refers to the contextualised social (and economic) relations of agents and firms which contain elements of reciprocity, consistent technological views and a vision of the ongoing nature of relations, and involve practices, such as jointproblem solving or information exchange, that go beyond a purely price-based exchange relationship. As such, network is related to a collective level of action that enables agents to access additional resources, such as specific information about markets and technologies or preferential contracts, which would not be available through individual action alone (Bathelt and Glückler, 2011). The network structure of clusters is situated within, but is not limited to, the local production system. Although the wider structure of input-output linkages of firms also becomes part of the economic context of agents in 
clusters, in practice, social and economic relations are inseparable indicating that traded and untraded interdependencies (Storper and Salais, 1997) are closely interwoven. As to traded linkages, the incompleteness of contracts leaves room for the development of trust (or distrust) between related partners in the negotiation and performance of economic transactions (Williamson, 1985). Mutual trusted relations become indispensable for traded interdependencies. Furthermore, social networks in some places originate out of economic rationales. Although not originally part of economic transactions, new personal relationships may be established over time through repeated economic transactions. Although it is the compellability and inspiration of personalities that trigger the formation of new social networks at a person-to-person level, economic transactions offer opportunities for interaction and communication based on which some personal relationships develop, and not others. At the regional level, personal social networks may exist before the formation of clusters. Such networks can become a key mechanism in the diffusion of market and technology information and develop into a cluster later on (Meyer, 1998).

Network resonates with the social-embeddedness argument of economic actions (Granovetter, 1985). However, in a cluster setting, a significant feature of the network concept is its dynamic capabilities when viewed over time. Changes in value and belief systems, advances in telecommunication technologies and the intensification of interfirm competition can trigger a transformation of personal interaction toward a broad societal level beyond the region. In Giddens' (1990) reflection of trust and ontological security systems between different societies, kinship relations provide a stable mode of organising personal relations in the pre-modern societal context. These relations have been substituted by relationships of friendship or emotional intimacy in modern society. It is thus reasonable to assume that for clusters in developing or transition economies, such as China, paradigms of social networks at the personal level 
will also change in the modernisation process. Such a change of basic personal networks has a substantial impact on strategic actions within clusters, yet to maintain personal relations requires regular interaction and communication. Networks in this sense are "as much process as they are structure, being continually shaped and reshaped by the action of actors who are in turn constrained by the structural positions in which they find themselves" (Nohria, 1992, 7). By viewing networks as dynamic connections within heterogeneous contexts that are shaped by collective and individual actions, the contextnetwork-action framework conceptualises deeper changes in the socio-economic structure of clusters.

Action. Even though context and network offer powerful insights into the behaviour of local agents, action per se still needs to be treated as a separate pillar in our framework because experience from action develops in a cumulative fashion, and agents learn based on their absorptive capability (Cohen and Levinthal, 1990). As opposed to network, action refers to the individual level of evaluation, decision-making and reflexive monitoring through which agents react to existing context and network conditions. This may reflect individualistic learning, strategic action to differentiate products from competition or a deliberate effort to choose a path that only partially reflects the needs of the network. At both the individual and organisational level, prior related knowledge helps and directs agents to use and assimilate new knowledge. The more specialised knowledge agents have previously acquired, the faster they can learn in their context or network. The role of absorptive capability of agents suggests that learning is a cumulative and path-dependent process with self-reinforcing characteristics. A conceptualisation of cluster evolution without action would bear the risk of over-emphasizing exogenous variables.

Action depends on specific personal and internal organisational structures and is related to learning opportunities. At the individual level, strategic rearrangement of a 
market leader or a decision of a key entrepreneur may have a great effect on the future structure of the cluster. Actions of other less pronounced agents would affect the cluster in a more incremental way or compensate one another. At the group level, however, collective action addresses the network level and has a stronger impact on cluster evolution than at the individual level, especially in developing countries (Humphrey, 1995). To make joint action possible, mutual trust of agents derived from their social networks is required, leading to a situation where network and action overlap and reinforce each other.

Interrelationships in the tri-polar framework. In our framework, action relates to individual firm/agent strategies and decision-making, while network is associated with the collective qualities of action in ongoing relationships which render additional resources, such as information flows or better customer access, not available through individual action. Context refers to the broader economic and institutional structures and stabilised patterns of relationships that provide the frame for individual and collective action and interaction. 5 The three pillars are closely interrelated and changes in structure and agency can be part of each pillar depending on which perspective is relevant. A cluster firm, for instance, may engage in strategic action and develop an improved technology. The firm may convince suppliers and customers to collaborate and establish networks. If successful, this action and networking may lead to new industry standards and that become part of the wider context. In other words, concepts such as organisation, network or innovation can be both structure as a specific form (e.g. an organisation) and process as the respective practices (i.e. the way how that organisation is organised). It depends on the perspective chosen how these aspects are reflected in the framework (e.g. customer interaction vs. wider market changes).

\footnotetext{
${ }^{5}$ Some parallels to this framework can be found in Clark and Tracey's (2004) family-community and Storper's (2004) community-society distinctions.
} 
In any case, context, network and action are equally indispensable. At the regional level, it is the interaction of these pillars that explains the evolution of clusters. Conceptualising cluster dynamics without recognising all three pillars provides merely a partial understanding. Only emphasizing the role of stable networks in local actions risks failing to understand diversifying patterns with transitional background, such as China's regional economies. Conceptualisations, which limit themselves to emphasizing the importance of external contexts for actions, conversely neglect the role of human agency in regional practices (Scott, 2006; Henn and Laureys, 2010).

In sum, the tri-polar framework offers a systematic way of studying and interpreting the evolution of clusters, yet it does not produce ideal-type cluster visions since the dynamics of the three pillars can work in both vicious and virtuous ways:

(i) Vicious cycles. We refer to interrelationships between the pillars as being vicious if they produce lock-ins and result in regional decline. In the literature, economic crises in industrial districts are often explained by changes in economic contexts, such as a sharp drop in demand or the appearance of a new technological paradigm. But a transformation of the external environment accounts for only one part in the overall stagnation of clusters. Weaknesses in the networks of a region can also be responsible for the rigidity of old industrial areas. Reasons for regional failure can be classified as different forms of lock-ins (Grabher, 1993; Eich-Born and Hassink, 2005) resulting from interrelationships between the three pillars. First, decades of action in infrastructure projects and subsidy programs may stabilise intensive relations between people and firms (network) in an industry and corresponding policy field, thus establishing a local conservative regime (context) that constrains further adjustment of local agents. The ossified institutional context results in "political lock-in". Second, long-term personal networks of local agents can result in similar reactions (action) to demand changes and technological opportunities. A homogeneous view of the world caused by intensive social 
networks in clusters may be related to "cognitive lock-in". Third, the stable demand for products may fixate the localised social division of labour and support a rigid economic context. The enduring fragmentation of activities among firms can result in shortcomings in the local agents' learning processes and investment decisions regarding R\&D. By exclusively concentrating on certain activities, the local agents' accumulation of knowledge becomes biased and absorptive capabilities with respect to new knowledge may be more restricted. In Grabher's (1993) classical typology, this rigidity of interfirm connections (economic context) generates "functional lock-in".

(ii) Virtuous cycles. In contrast to the above, virtuous interrelations between the three pillars can develop that have positive effects. Agents with overlapping knowledge bases are, for instance, motivated to cooperate and communicate (Nooteboom, 2000). Through the action and interaction of diversified agents, knowledge circulates in clusters; ideas collide; and innovation becomes more likely. In turning innovative ideas into business successes, the agents' relationships (network) that were established in previous interaction are reinforced. Some commercialisation of innovation may fail but there are also successes, which may re-order the existing industrial structure (economic context) and change the existing cluster path. Successful cooperation of agents not only results in economic returns to innovation but may also establish new interpretations of the context within which the agents are situated while producing important knowledge of their strengths and weaknesses. Agents with enhanced reflexive capability with respect to their context are more likely to act in anticipation of, rather than react to future changes.

At the regional level, clusters with pro-active agents across different networks are characterised by high adaptability. This can lead to dynamic processes of path creation. Along with dynamic interactions of agents, mutual expectations regarding the coordination of actions may turn into unconscious routines and norms (institutional context), which become new components of the overall intangible regional assets. In the 
long run, these regional assets - both social networks and routines of doing business are thus also constructed, sustained and altered through social reproduction. For instance, both the arrival of new immigrants and the succession of a new generation of entrepreneurs impact regional assets. The interaction of context, network and action in virtuous cycles actively drives a regionalised structuration process, similar to the conceptualisation described by Giddens $(1984) \cdot{ }^{6}$

Finally, we need to emphasize that vicious and virtuous cycles are two extreme scenarios. In reality, interrelationships of components of the tri-polar framework rarely operate in a uniform direction. We are more likely to find that elements of vicious and virtuous cycles co-exist, allowing for temporary stabilisations of power relations within cluster evolution without necessarily leading to either extreme case. Similarly, the tripolar framework should not be viewed as an ideal-type model of cluster evolution but as a framework for the analysis of cluster dynamics.

Application to Cluster Evolution in China. The tri-polar framework seems particularly appropriate in the analysis of cluster dynamics in China because here the economic structures and practices associated with the three pillars are in a process of ongoing, often discontinuous, changes. First, the transition to a market economy restructures the context for the genesis and development of clusters. Most clusters in coastal areas of China have emerged after the introduction of open market and reform policies in the 1980 s and 1990 s and developed along the way of China's integration into the world economy. This dynamic economic, social and institutional background provides the context in which clusters are situated, requiring constant adjustments and adaptation.

\footnotetext{
${ }^{6}$ Regionalisation here refers to a geographical concept rather than to Giddens' (1984) conceptualisation that defines structuration categorically in a scale-free manner (Gregory, 1989, 200). Our goal in the tri-polar framework is to integrate everyday action and broader systemic influences to be able to consider both agency and structure simultaneously. As such, this framework sympathises with Giddens' (1984) structuration perspective and uses it as a metaphor.
} 
Second, the dominance of traditional social networks based on kinship ties (as well as hierarchical power relations established during the communist regime) is increasingly challenged by friendship relations that develop in modern society. The social structure in the traditional Chinese society is organised through such kinship relations or guanxi networks, where each individual is situated at the centre of an egocentric network extending along kinship ties without explicit boundaries. This is similar to "the cycles that appear on the surface of a lake when a rock is thrown into it" (Fei, 1992, 60).7 Since many industrial clusters in China have been formed in rural areas where this traditional social structure was strong, we can expect that kinship networks played a substantial role in the diffusion of market and technological knowledge in the initial formation of clusters (Xiang, 2005). Conversely, in urban areas with state-planned businesses, strong hierarchical ties shaped the rise of state-centred, large-firmdominated clusters. With the transformation of society and economy and the maturation of legal configurations, the role of traditional guanxi networks changes and sometimes declines (Guthrie, 1998; Hsu and Saxenian, 2000), thus affecting the role of social networks in the later stages of cluster evolution.

Third, those entrepreneurs who shaped the formation of industrial clusters in China during the transition period are now retiring from work. The succession of a new generation of entrepreneurs with different knowledge, experience and views of the world brings "fresh air" into the local community, while, at the same time, challenging existing cluster structures. To illustrate the effects of these changes in China and the usefulness of our conceptual framework, we investigate a specific cluster in Guangdong province.

\section{Research Practice and Data Collection}

\footnotetext{
${ }^{7}$ Fei's (1992) famous concept to describe this social network structure in traditional Chinese society is referred to as "chaxugeju”, or the differential mode of association.
} 
The empirical findings presented draw from three years of research in the aluminium extrusion industry cluster of Dali. From 2007 to 2009, on-site fieldwork was conducted to collect primary data about the structure and changes of this cluster, as well as about the three pillars of context, network and action. Our research was qualitative and explorative in nature (Eisenhardt, 1989). It follows the tri-polar framework and, at the same time, develops it further.

During the fieldwork, a total of 34 face-to-face interviews were conducted with 27 entrepreneurs, each lasting at least one hour. Aside from this, seven interviews were conducted with local government officials and another eight interviews with representatives of the local business association. Furthermore, several group discussions involving multiple entrepreneurs from different firms were conducted and systematic field observations carried out. The selection of firms and entrepreneurs was guided by the local industry association, which also helped to increase participation in this research. In total, 15 firms rejected to our interview requests resulting in a response rate of approximately 70 per cent. Compared to the overall number of about 100 firms in the region, this selection can be assumed to be representative of the most important structures and trends in the cluster - although this was not necessarily a goal of our research.

In a step-by-step procedure, the gradual establishment of personal relationships with key informants in the community revealed the "story" behind the cluster's genesis and evolution. In the first stage, we investigated the general structure of the cluster through semi-structured interviews and factory tours. Parallel to this, we took a detailed look into the history of China's aluminium industry. This included the analysis of a database of industry news from 1984 onwards, as well as databases of court cases and patents of the aluminium industry in China. 
The second stage of interviews enabled us to discuss our understanding of the industry and its evolution "in close dialogue" (Clark, 1998), as the interviewees were familiar with our research. At this stage, we abandoned the more structured method originally applied, which required interviewees to answer predefined questions. Instead, we established an open-ended communication environment (Miles and Huberman, 1994). We decided to give up a researcher-dominated conversation style since we did not know much about the deeper context of actions and networks in the cluster and did not want to influence our informants' narratives by preliminary impressions (Silverman, 2001). Projections of the history of the local industry and its changes over time are stored in the memories of our interviewees. An evaluation of the social networks involves the interviewees' emotions and feelings. Significant events and changes in the local community can only be revealed by giving these individuals the freedom to choose from their mind. Since the experience and interpretation of such information is unique and personal, we did not define the specific topic to be discussed before each interview, but let the interviewees select. As such, the threads of the topics in our interactive conversations were based on improvisation, and interesting examples or stories were chosen by the interviewees. Even if they were sometimes less willing to talk about their own networks, they would likely describe the specific structure of local networks and indicate who is friend with whom. Networks were identified through such peer comments and triangulated based on the comments of others. From this point of view, we share the spirit of oral historians in these conversations (Tonkin, 1992).

In the last stage of the fieldwork, we owe an enormous debt of gratitude to the Guangdong Technical Innovation Centre for Nonferrous Metal Industries, a prestigious non-governmental organisation of the local aluminium extrusion industry, which generously shared materials and documents about the cluster with us. The evolutionary development presented below is based on all of the above-described research practices. 
Triangulation between the different sources was used to verify interview information and distinguish more from less consensual views (Baxter and Eyles, 1997).

\section{The Rise of a Cluster in the Transitional Context of Dali}

The aluminium extrusion industry cluster in Dali, although similar to clusters in other manufacturing industries, appears somewhat unusual in the context of the aluminium industry. In this industry, the upstream segments of production, such as bauxite mining, aluminium refining and smelting, are highly integrated at the firm level and dominated by multinational enterprises, such as Alcoa, Rio Tinto Alcan and RUSAL. However, the extrusion segment of the industry exhibits a different industrial structure (Stuckey, 1983). Generally, extrusion firms buy aluminium ingots and auxiliary material, melt and push them under pressure through dies (extrusion process), coat surfaces by anodising or powdering, and finally deliver aluminium profiles to customers. In extrusion batches, aluminium profiles are usually specified by the customers. Thus, scale economies in the extrusion sector are not as significant as in the upstream segments of production. Since extrusion profiles differ from batch to batch, vertical integration with major upstream aluminium producers does not have significant advantages. As a result, most integrated producers do not engage in extrusion activities. ${ }^{8}$

The separation of extrusion activities from primary aluminium production has led to the development of unique spatial patterns of aluminium extrusion. A high sensitivity of aluminium ingots and profiles regarding transportation costs usually leads to a dispersed spatial pattern of the aluminium extrusion industry to meet the expectations of local demand. At a global scale, the locations are thus scattered

\footnotetext{
${ }^{8}$ Of the big three primary aluminium producers, RUSAL and Rio Tinto Alcan do not engage in extrusion activities. Alcoa, the most integrated producer, exited the soft alloy extrusion business in 2009 and only remains in the hard alloy extrusion segment of the industry (based on information from various corporate websites).
} 
(Rüttimann, 2004). Dali, however, is an exception to this rule as the region is characterised by a remarkable agglomeration of extrusion firms (Figure 2). The rise of this industry in Dali shows how social, institutional and contextual specifications can overcome the impact of technological regularities on an industry's spatial configuration.

Figure 2 about here

The formation of the aluminium extrusion industry in Dali was not predictable and can only be understood by revealing the specific interrelationships and interactions of firms that were enabled by the national reform context and the role of local industrial traditions. Dali, a "small town" west of Guangzhou (Figure 2), has a long history of metal recycling and melting. In the 1920 s and 1930s, entrepreneurs from several villages of Dali gathered along one particular street in Guangzhou where they collected scrap metals to be melted in Dali (Committee of Dali Chronicles, 2008). This tradition of metal recycling relates to the later rise of the aluminium extrusion industry. It became particularly significant in the early 1990 s when a different political-economic context was in place. With the transition from a central planning to a market-oriented economy, China initiated housing system reforms that triggered a boom in construction. Changes in the institutional and economic context of housing systems generated a huge demand for aluminium profiles. At that time, aluminium ingots were controlled by state-owned enterprises and distributed through the central planning system at a price of 4,00o Yuan (ca. 500 US-Dollars) per ton. However, after simple extrusion and coating, aluminium profiles could be sold at nearly 30,000 Yuan (ca. 3,750 US-Dollars) per ton (Chen, 1989). The extraordinary profit margins would have triggered manifold investments in the industry, but government intervention initially slowed down the growth. The reason behind this intervention was that national key infrastructure projects were negatively 
affected by an insufficient supply of aluminium due to high private industry demand (Li, 1989). The national government secured access to aluminium by cutting off the private extrusion firms' supplies from state-owned primary aluminium producers. ${ }^{9}$ Without these suppliers, scrap-aluminium recycling was the only possibility for private extruders to survive and succeed in their business. It was under this specific context that Dali's recycling tradition was revived and became a critical element for the industry's evolution. The matching of national contextual changes with local traditions accounted for an unparalleled growth of the aluminium extrusion industry since the early 1990 (Figure 3).

Figure 3 about here

$* * * * * * * * * * * * * * * * * * * * * * * * * * *$

As argued in the tri-polar framework, a cluster is not an organism that can grow by itself. To understand its evolution, we need to investigate the context, network and action framework and the reflexive interrelationships between these pillars, rather than just point at changes in the national context and local traditions. The genesis of a cluster results from collective choices and actions of local entrepreneurs, suggesting that we must employ a micro-level agent-based approach to understand Dali's development. To accomplish this, it is necessary to revisit the decision-making processes of local entrepreneurs at the time. For potential entrepreneurs in rural areas, aluminium extrusion was more sophisticated than other traditional production, such as garment manufacturing. In addition to costly equipment, the production of aluminium profiles required sound knowledge of the material properties and the extrusion process, some of which was tacit and was not part of the original local knowledge pool in Dali. Thus, despite the huge demand in the early 1990s, aluminium extrusion was a risky investment.

\footnotetext{
${ }^{9}$ Another intervention to restrict the growth of the industry was to prohibit the use of aluminium windows and doors in government buildings. This policy to control demand, which was enforced in 1989, was, however, not as effective (Li, 1989).
} 
This led us to the question how, following Storper and Walker (1989), windows of locational opportunities were exploited or opened up by local agents in this specific context? An answer to this is provided below by exploring the learning processes (see, also, Miao et al., 2007) of local entrepreneurs in Dali.

The story of local learning processes in Dali's aluminium extrusion industry illustrates how traditional social networks and local culture stood out in knowledge dissemination during the early stages of development. Interestingly, local learning networks in Dali differed according to knowledge types. For real-time market information of aluminium ingots and profiles, an intensive learning culture was established based on the specific local lifestyle and existing social practices. In the early 1990s, without modern communication systems, the only efficient way of getting information about material and product prices and to catch up on industrial dynamics came from daily meetings with ingot sellers, profile customers and other extruders. The entrepreneurs established a culture of face-to-face communication by regularly sharing information over brunches in teahouses. Through this old Guangdongese tradition, they created to some extent a "community of practice" in these teahouses where working, learning and local culture were united in a natural way (Brown and Duguid, 1991). ${ }^{10}$ One local observer remarked:

Every morning when walking into 'the Happy City', the biggest teahouse in Dali, you will find eighty-six tables in the lobby without a single vacant seat. Nearly 1,000 people gather here every morning, talking aluminium with each other ... I sit in a corner and learn that the table beside me has been ordered for years by Hualian Aluminium Company. Many local aluminium extruders have done this in the same way. A sales representative on the table says: 'My job is having brunch here. Since prices of aluminium ingots and profiles change every day, I have to be here to know that. Look, the guy with glasses is my boss. He is

\footnotetext{
${ }^{10}$ The term "community" is used here as a description of the local collaborative "atmosphere" of knowledge sharing and interactive learning in the "teahouse lives" of aluminium extrusion entrepreneurs who had a common interest and a joint identity.
} 
talking business with a customer from Zhejiang province'. (Song, 1993, 2; translated from Chinese)

Interestingly, these teahouse get-togethers created a new professional career path: the aluminium information broker. Such a broker typically charged a three to five per cent facilitation fee per contract after successfully connecting an aluminium extruder with a supplier or customer (Song, 1993). Thus, the communication of market and raw material information and the connection of supply and demand were exploited by local brokers in teahouses. This phenomenon demonstrates a strong component of economic rationality behind the local learning culture.

For technical knowledge, however, a different learning network was formed based on traditional kinship relations. It was impossible to acquire such knowledge in teahouses for two reasons: First, it was hard for local entrepreneurs without professional training to precisely articulate specific technical problems. Problems encountered in the production process could be more easily understood and solved through on-site visits and observations, rather than off-side discussions. Second, during the early stages of cluster formation, there were only few pioneering entrepreneurs with a sound technical background and practical knowledge of aluminium extrusion. Our interviewees pointed out that most attendees in teahouses were lacking knowledge and interest in technical fields. To accumulate technical knowledge in production, a pioneer-centred learning network developed based on kinship relations. In the context of material shortages in the early 1990s, local entrepreneurs realised that entering the industry was very profitable. As traditional Chinese society emphasizes an individual's responsibility for the family (Freedman, 1961), much of the production knowledge of aluminium extrusion disseminated along the entrepreneurs' kinship networks. Following the pioneers' differential modes of association (Fei, 1992), production knowledge first spread to 
immediate family and close friends, and later to more distant connections. An early entrepreneur described his learning linkages with one local pioneer as follows:

Kwang's ${ }^{11}$ father, an old hardware man, was very famous. He engaged in the metal business since the Great Leap Forward and entered into the aluminium extrusion industry at the beginning of policy reforms. We learned how to extrude aluminium in the early 1990 s through our relatives and close friends. At that time, seeing he [Kwang's father] could make money in the aluminium extrusion business, we went close to him. I did not know him, but one of my friends is his relative. We all called him 'old master' and asked him for help whenever we had a problem. (Interview in 2008; translated from Chinese)

With a small number of pioneering entrepreneurs in the centre that were connected through differential modes of association, a tightly-knit network of knowledge acquisition and learning was woven in Dali based on traditional local social relations. Even though the emerging cluster was not a hub-and-spoke district (Markusen, 1996) with central organisations that were connected to others through traded linkages, it exhibited a hub-and-spoke structure in the form of untraded learning linkages. This pioneer-centred network was unstable, however, in the sense that local agents depended on few individuals for learning and problem solving. The removal of one or few of the pioneers would have had catastrophic effects to the entire local community. Unfortunately, this actually happened in Dali in the aftermath of a traffic accident in the early 1990s:

One day, when Liang [a pioneering entrepreneur] and several of his relatives walked to a restaurant, they were hit by a truck. Three persons, including Liang, were injured and Liang died in Foshan No. 1 Hospital. At that time, many entrepreneurs in Dali had learned a lot from Liang on how to build aluminium extrusion plants, operate machines and many other things. So, on the night when he was in hospital, dozens of entrepreneurs went to see him

\footnotetext{
${ }^{11}$ All names mentioned during the interviews were changed to guarantee anonymity.
} 
spontaneously. When doctors regretted their inability to save his life, those entrepreneurs cried in desperation. (Interview in 2008; translated from Chinese)

In a moving way, these feelings of sadness reveal how intensive and personal the kinship-based learning network had become. Ongoing knowledge acquisition and learning were significant contributions of kinship networks to the formation of the cluster, yet not the only ones. In a transitional context, like that of China's aluminium extrusion industry, not only market and practical knowledge were required, but also substantial start-up capital. Formal institutions were not a reliable source for potential entrepreneurs since the financial system was influenced by national industrial policies to restrict investments in aluminium extrusion. Even where banks existed, local entrepreneurs starting from scratch were often not able to provide the required securities to acquire sufficient start-up capital. Thus, borrowing money from relatives and the early pioneers became the main source of financing for these entrepreneurs. In this way, kinship networks not only disseminated technical knowledge, but also provided start-up capital in the early cluster development. One interviewee remarked:

Dong [an entrepreneur] started with a small cheap extrusion machine. At that time [in the early 1990s], his mother worked in the aluminium extrusion industry and had close relationships with two pioneering entrepreneurs. So, his mother said to these pioneers: 'Hi, my child has nothing to do. Why not give him a cheap machine to let him help you fill some small orders?' With a small machine [provided by these pioneers], Dong entered the industry and later developed further. (Interview in 2008; translated from Chinese)

The nature of this kinship-network-based development had a clear spatial impact that resulted in a unique spatial pattern of the regional aluminium extrusion industry. In a pre-modern society with little migration, kinship relations formed by marriage and reproduction were very parochial (Fei, 1992). As typical in traditional rural China, most relatives who were part of these networks lived in the same or a nearby village. Since knowledge dissemination and capital accumulation were mainly realised through 
kinship-based networks, the spatial pattern of the aluminium extrusion industry was characterised by strong agglomeration tendencies at the village level. Figure 2 shows the results of this clustering process very clearly. Even within the "small town" of Dali, the industry revealed an uneven spatial distribution with concentrations in several villages, including Lian Yao, Li Xi, Shui Tou, Cao Bian, Xie Bian and Tan Bian. The aluminium extrusion plants were located close to the main highways indicating a distinct transportation-cost sensitivity. Also, Figure 2 shows that the development of the industry was accompanied by activities in related branches, such as mold casting, equipment manufacturing, scrap-metal melting and recycling. As a consequence, Dali developed into a fully-fledged cluster with customers that extended from Guangdong to cover the whole south of China.

\section{Network Erosion and New Path Creation in a New Context}

The kinship-based learning network in Dali enabled the rise of an aluminium extrusion industry cluster, but also restricted its later upgrading. Through local learning processes around the practices of few pioneers, more and more firms had become involved in aluminium extrusion. However, pioneer-centred mutual learning led to homogenisation tendencies in both the local knowledge base and the practices of the entrepreneurs. In the formation period, imitation practices of local firms resulted in low quality standards of aluminium profiles. In 1993, a random test of aluminium profiles in Guangdong, most of which were made in Dali, showed that only half of the 126 sample products tested would pass national standards (Anomynous, 1993). Again, in 1996, 12 of 17 aluminium profiles failed quality tests in Beijing, nearly half of which came from Dali (Anonymous, 1996). Similar to clusters in Zhejiang province (Wang, 2001), the imitation practices in Dali resulted in a negative regional reputation regarding product quality. However, given the lack of local related knowledge and the shortage context during 
China's transition period, it appeared necessary for early entrepreneurs to take imitation strategies and learn from local pioneers. Changes in the economic context initiated a shift in the tri-polar framework as indicated in Figure 4.

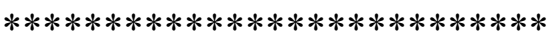

Figure 4 about here

$* * * * * * * * * * * * * * * * * * * * * * * * * * *$

With the deepening of economic reforms as well as an increasing domestic supply of aluminium ingots following significant innovations in upstream segments of the industry, the central government lifted restrictions on aluminium extrusion investments in the mid 1990s. As a result, existing extruders expanded and more firms were started up in Dali and elsewhere. Gradually, this changed the market conditions of the industry. From the late 1990s, the overall production capacity of aluminium extruders already exceeded domestic demand (Cao, 2002), even though capacity was still growing. In this buyer's market, domestic customers became increasingly demanding in terms of quality and style. As indicated in Figure 3, Dali's aluminium extrusion industry changed from quantitative expansion to a consolidation period without new entrants. The number of local aluminium extrusion firms remained at around 100, while employment stayed above 15,000. In this stage, new path creation seemed unlikely since the early entrepreneurs shared views that were too homogeneous. Our interviewees indicated that they expected the domestic construction market to continue to flourish; their familystyle management to continue to work well; and intense networks with local friends and relatives to enable survival.

However, the old development path began to change with the succession of a new generation of entrepreneurs. As owners of family enterprises, most local entrepreneurs intended to pass their business on to their children. Similar to what happened in some traditional industrial districts in Italy (Hadjimichalis, 2006), however, some of the new 
generation did not follow their parent's rural career path and, instead, moved to large urban centres. While this could have had disastrous consequences for the local industry, it did not lead to severe problems in the case of Dali. One of the interviewees explained why:

I [an early entrepreneur] have a daughter [working in the family business] and a son. My son, now a junior student in college, studies computer science in Zhuhai. It doesn't matter whether or not he returns [at this point]. He wants to work in Shanghai. Some of the new generation first say they will not work for their parents. However, after several years of working outside, they return. It is hard to create a new business now. (Interview in 2009; translated from Chinese)

Having started their business in their 30s, many early entrepreneurs are now approaching retirement. Even though some early entrepreneurs said that they did not want to retire, there is still a need to let the new generation take charge of the family business. Contrary to the intergenerational lock-in in Wenzhou (Wei et al., 2007), but similar to the progression of generations in a Japanese garment cluster (Yamamura et al., 2003), the new generation in Dali differed in substantial ways from their parents. In the context of cluster evolution, the most significant distinguishing characteristic is their loose connection with others, which has led to a significant erosion of local networks. Along with this, mutual learning networks among entrepreneurs have evaporated. One entrepreneur described the differences in communication patterns between the two generations as follows:

It is certain that communication in our generation is not as intensive as that in my father's generation. Now, we hire somebody from the labour market when we have a technical problem, rather than asking others as my parents did. I meet some of my peers at the conferences organised by the local business association. We do not know each other well. (Interview in 2008; translated from Chinese) 
Changes in the socio-economic context and in technological and career choices have intensified the erosion of local networks. First, the younger generation does not share as many joint experiences as their parents did. Early entrepreneurs knew each other from birth. Lifetime familiarity provided a natural basis for the development of trust. Entrepreneurs of the new generation have a different lifestyle and experience; they were sent to prestigious schools in urban settings and were separated from one another since childhood. Without knowing each other's past, they were strangers to each other upon their return to Dali.

Second, the diffusion of modern communication technologies replaced the need for continuous face-to-face encounters in sharing information. In 2000, the industry introduced a computer-based system to disseminate market information about aluminium ingots, and, by 2005, the entrepreneurs received regular market information on their cell phones. With these technologies, the new entrepreneurs did not need to discuss ingot prices face to face in teahouses as their parents did. Consequently, opportunities to build social networks based on ongoing face-to-face contacts disappeared.

Third, the choices of career paths by the new generation led to minimal communication with each other. Despite the lack of early interaction and the shift in communication channels, possibilities to get connected with other local entrepreneurs still remained, if given time. Yet, specialised career choices of young entrepreneurs made mutual connections less likely. Unlike their parents who knew everything about the aluminium extrusion business, the new generation increasingly focused on management and finance and had less knowledge of and interest in technology and production. Finance and management capabilities, in turn, were based on firm-specific information that is generally less likely to be shared with others. One entrepreneur who inherited 
business from her father in 2000 commented about the different career choices as follows:

My father's generation that started from scratch knows everything on aluminium extrusion: from production, to finance, to machine, to marketing. Of the thousand kinds of aluminium profiles, they can describe each in detail. But in our generation, we are specialised. I do not know profile production. If you talk about anodising or coating profiles, I know what you mean, but I do not know specific details. We are different from my father's generation. (Interview in 2008; translated from Chinese)

Although still in its infancy, the formation of a new generation of entrepreneurs with loose connections among one another substantially changed the nature of the existing cluster within and between firms:

(a) Within-firm context. A new generation of entrepreneurs grew up in a modern society and aimed to professionalize the management of their family businesses. While early entrepreneurs, who were socialised in the traditional patriarchal culture, operated production through verbal rules and personal relations rather than administrative manuals and guidelines, the new generation of formally trained entrepreneurs had a different mind-set preferring professional management with codified regulations. ${ }^{12}$ One entrepreneur in the new generation illustrated this:

In my father's age, the administrative manual was only few pages since what he said was the rule. But now this does not apply. We need to be formal. Here is the new administrative manual I revised last year, very thick. What you say does not count. It needs to be in black and white. I will revise it again next year. It will be [even] thicker. (Interview in 2008; translated from Chinese)

(b) Between-firm context. As a consequence of the new socio-economic context, the erosion of networks changed the previous collaborative learning relations into more

${ }^{12}$ Among other reasons, this was related to changes in the legal system (i.e. the increasing juridical power of workers to protect their rights), a different educational background and a lack of personal reputation and networks. 
competitive relations. Originating from the pioneering entrepreneurs, aluminium profiles originally shared common styles, which, to some extent, turned into public goods within the local community. New entrepreneurs later recognised and exploited intellectual property rights, which were incompatible with the early structure. This change was propelled by an increasing number of court cases about intellectual property rights. In particular, one knowledgeable local leader claimed patents for aluminium profiles in 1999 and began suing other local firms for illegally imitating his styles in 2003 and thereafter. The number of court cases on intellectual property issues in Dali increased from 6 in 2003 to 17 in 2005 and 12 in 2007. ${ }^{13}$ From 2003 to 2007, the total number of court cases regarding intellectual property rights of aluminium profiles added up to 59. This is a significant number considering that there are only about 100 aluminium extruders in the cluster. In response to these trials and the changing intellectual property context, most local firms ceased former practices of mutual learning based on face-to-face discussions and switched their focus to intra-firm R\&D. In our fieldwork, the new generation of entrepreneurs confessed that they no longer authorised plant tours for the local community. This emphasis on intra-firm research resulted in a dramatic increase of regional patents, from 25 in 1999 to 184 in 2003 and 616 in 2006. Even after the global financial crisis, the region accounted for 240 patents in 2009.14

Even though most of the patents focused on design issues rather than technology, the increase in patenting indicates that Dali is on the way to develop an innovative cluster structure or to create a new path. While the changes in the socio-economic and political context of production led to a weakening of traditional network relations, this

${ }^{13}$ This data was retrieved from the Database of China Court Cases

(http://www.lawyee.net/product service/db case.asp, accessed 8 September 2009), which was established by the Law School of Peking University. It is the largest database of court cases in China.

${ }^{14}$ Patent data was retrieved from the website of China Intellectual Property (http://www.cnipr.com.cn/, accessed 9 September 2010). This database was established by the State Intellectual Property Office of China and includes information about intellectual property in China since 1985. It is updated on a weekly basis. 
did not cause a decline of the overall cluster. New patterns of work, professional management and intra-firm research generated new patterns of innovation based on competition in design rather than cooperation in technologies. Although it is too early to evaluate the long-term consequences and durability of these changes, our interviewees reported increased competitiveness as a consequence.

\section{Conclusion}

In discussing a dynamic perspective of industrial clusters, this paper formulates a tri-polar analytical framework that combines the concepts of context, network and action in a coherent way. The usefulness of this framework is illustrated in a regional case study of the aluminium extrusion industry in China. In the early 1990s, the construction boom related to the national economic reforms and the state-controlled nature of supplies provided a unique locational opportunity to establish an aluminium extrusion industry in Dali. Based on a long scrap-metal recycling tradition, clustering was related to intense learning of local entrepreneurs that were embedded in traditional kinship-based networks. The early growth was led by few pioneering entrepreneurs. Practices of technological learning and acquiring finance through strong local network relations lowered the entry barriers for new entrepreneurs with little prior experience. As a consequence of this path, the rise of the cluster resulted in a homogenous product structure and agents sharing similar views. In this vein, the early industry structure in Dali had characteristics similar to those of old industrial districts in Europe with cognitive lock-ins. However, with the change of the political-economic context and the succession of a new generation of entrepreneurs, the cluster experienced deep structural transformations. This did not halt the development of the cluster, but led to initiatives encouraging new path formation. At the centre of these transformations were the new entrepreneurs, who grew up in modern society and were socialised through the higher- 
education system. These entrepreneurs differed from their parents' generation not only in terms of knowledge and world views, but also in their participation in social and economic networks. As a result, close networks among new entrepreneurs were rare. In the new context of abundance of material supplies, the new generation of entrepreneurs adopted a novel formal management style and increased investments into intra-firm research to compete with each other on the basis of quality and innovation. Altogether, new path creation appeared to have strengthened regional competitive advantages.

The case of Dali provides a number of insights to the conceptualisation of cluster evolution. First, the concept of network is relational in nature, and should be interpreted in a contingent way (Bathelt and Glückler, 2011). Past research has viewed clusters often in static terms. Research on networks in clusters has focused on the intensity of existing linkages, generally assuming that such ties are responsible for regional success or failure. The dynamics of Dali's aluminium industry casts doubt on the explanatory power of a static network concept. The erosion of local networks from strong kinship-based relations of the former generation toward loose connections of the new generation of entrepreneurs is essential to understand the deeper transformations in the cluster path. This shift partly supports Granovetter's (1973) and Grabher's (1993) combined arguments of the strength of weak and the weakness of strong ties. However, without the intensive learning processes in strong kinship-based relations in the early stages, the cluster would not have emerged in the first place. A more appropriate interpretation of networks in the case of Dali is that both strong and weak ties were important for cluster evolution, but they mattered in different ways at different times and in different contexts. It is therefore problematic to evaluate the impact of strong or weak ties on clusters without considering the specific context. The contingent value of networks has thus far been primarily discussed at the individual and organisational level in management studies (Burt, 1997; Gulati and Higgins, 2003). 
Second, local traditions of interaction should, in a similar fashion, be evaluated in the specific context in which they matter for cluster evolution. Contextualised interpretations provide a perspective to understand why history matters in a nondeterministic way. In the early 1990s, reforms in housing regulations created a huge demand for aluminium profiles, at a time when the restricted aluminium distribution system provided a unique locational advantage for Dali with its tradition of scrap-metal recycling. It is under this specific context that opportunities for learning and involvement among local entrepreneurs emerged. With a new political-economic context, new practices of interaction among individuals and organisations formed and became new elements of local structures and traditions. Thus, the degree to which a regional path restricts or enables agents' choices depends on the specific context within which the local agents are situated (Storper, 2009b).

Third, the evolution of clusters is shaped by the aggregated action of local agents, as well as the unintended consequences of this action (Merton, 1936). Since some contexts are out of the hands of the local agents, action may have unintended effects that shape future settings and affect individual and collective action in the next round. In Dali's early development, local entrepreneurs expanded production and encouraged new entrants. These actions changed the structure of the industry, which unintentionally put an end to imitation strategies later on. When older entrepreneurs sent their children to urban schools, they expected them to receive a better education, but did not intend to erode existing networks. These unexpected consequences significantly altered the trajectory of the cluster.

Combing these important pillars, our tri-polar framework conceptualises cluster evolution through systematic interrelationships and ongoing feedback between context, network and action. In drawing from a single case study, however, we are aware of the potential limitations of our analysis. One drawback is the geographic focus on a single 
regionally-/nationally-oriented industry cluster within China's unique politicaleconomic transition context. As such, we do not face a situation where multinational corporations and other global influences have directly and significantly impacted this framework until now. Although other empirical cases encourage us to assume that a similar framework can also be applied to more advanced economic contexts involving systematic global-local interrelations, connections to or even conflicts with global value chains or production networks require further investigations and systematic case studies.

\section{Acknowledgements}

We would like to thank Alexandra Eremia, Ben Spigel, Robert Hassink, Diana Rasmussen, Neil Wrigley and two anonymous referees for their comments on earlier drafts of this research. Our sincere thanks are also due to Xiu Jiayu, Li Peiyi and Zhai Guojun for their help in coordinating the fieldwork and to the entrepreneurs in Dali who shared their insights and stories with us. Parts of this paper were presented at the Annual Meeting of the Association of American Geographers in Las Vegas 2009, supported by a Travel Award of the China Specialty Group which is greatly appreciated. We are grateful for the comments received from the participants of this meeting and the thoughtful remarks of two anonymous reviewers of the China Specialty Group. We also wish to acknowledge financial support through the High-level University Graduate Student Overseas Study Program of the China Scholarship Council, the National Natural Science Foundation of China (Grant No. 40535027) and the Canada Research Chair Program of the Social Sciences and Humanities Research Council of Canada.

\section{References}

Abernathy, W. J., Utterback, J. M. (1978) Patterns of industrial innovation, Technology Review, 80: 40-47. 
Amighini, A., Rabellotti, R. (2006) How do Italian footwear industrial districts face globalization? European Planning Studies, 14: 485-502.

Amin, A. (1999) An institutionalist perspective on regional economic development, International J ournal of Urban and Regional Research, 23: 65-78.

Anonymous. (1993) Junye construction aluminum profiles on strong sales, China Enterprises, 18 January, 1 (in Chinese).

Anonymous. (1996) Low qualified rate of aluminum profiles in Beijing, China Construction Materials, 25 October, 2 (in Chinese).

Bathelt, H. (2009) Re-bundling and the development of hollow clusters in the east German chemical industry, European Urban and Regional Studies, 16: 363-381.

Bathelt, H., Glückler, J. (2003) Toward a relational economic geography, Journal of Economic Geography, 3: 117-144.

Bathelt, H., Glückler, J. (2011) The Relational Economy: Geographies of Knowing and Learning, Oxford: Oxford University Press.

Baxter, J., Eyles, J. (1997) Evaluating qualitative research in social geography: establishing "rigour" in interview analysis, Transactions of the Institute of British Geographers, 22: 505-25.

Becattini, G. (1990) The Marshallian industrial district as a socio-economic notion, in F. Pyke, G. Becattini and W. Sengenberger (eds) Industrial Districts and Inter-firm Co-operation in Italy, pp. 37-51. Geneva, International Institute for Labor Studies.

Boschma, R., Iammarino, S. (2009) Related variety, trade linkages and regional growth in Italy, Economic Geography, 85: 289-311.

Bresnahan, T., Gambardella, A., Saxenian, A. (2001) "Old economy" inputs for "new economy" outcomes: cluster formation in the new Silicon Valleys, Industrial and Corporate Change, 10: 835-860. 
Brown, J. S., Duguid, P. (1991) Organizational learning and communities of practice: toward a unified view of working, learning, and innovation, Organization Science, 2: $40-57$.

Brusco, S. (1982) The Emilian model: productive decentralization and social integration, Cambridge J ournal of Economics, 6: 167-184.

Burt, R.S. (1997) The contingent value of social capital, Administrative Science Quarterly, 42: 339-365.

Camagni, R. (1991) Local "milieu”, uncertainty and innovation networks: towards a new dynamic theory of economic space, in R. Camagni (ed) Innovation Networks: Spatial Perspectives, pp. 121-144. London: Belhaven Press.

Cao, W. (2002) The biggest aluminium extrusion production base is built in Sanshui, Guangdong Province, China Nonferrous Metal News, 11 April, 3. (In Chinese).

Chen, Y. (1989) Exploring nonferrous metal markets: where is aluminium going? The Economic Daily, 1 January, 1 (in Chinese).

Chiarvesio, M., Di Maria, E., Micelli, S. (2010) Global value chains and open networks: the case of Italian industrial districts, European Planning Studies, 18: 333-350.

Clark, G.L. (1998) Stylized facts and close dialogue: methodology in economic geography, Annals of the Association of American Geographers, 88: 73-87.

Clark, G.L., Tracey, P. (2004) Global Competitiveness and Innovation: An Agentcentred Perspective, Houndsmill, New York: Palgrave Macmillan.

Cohen, M., Levinthal, D.A. (1990) Absorptive capacity: a new perspective on learning and innovation, Administrative Science Quarterly, 35: 128-152.

Committee of Dali Chronicles. (2008) Chronicles of Dali Town, Guangzhou: Guangdong People's Publishing House (in Chinese).

Cooke, P., Morgan, K. (1994) Growth regions under duress: renewal strategies in BadenWürttemberg and Emilia-Romagna, in A. Amin and N. Thrift (eds.) Globalization, 
Institutions, and Regional Development in Europe, pp. 91-117. New York: Oxford University Press.

Eich-Born, M., Hassink, R. (2005) On the battle between shipbuilding regions in Germany and South Korea, Environment and Planning A, 37: 635-656.

Eisenhardt, K.M. (1989) Building theories from case study research, Academy of Management Research, 14: 532-550.

Fei, X.-T. (1992) From the Soil: the Foundation of Chinese Society, transl. by G.G. Hamilton and Z. Wang. Berkeley: University of California Press (originally published in Chinese in 1947 as Xiangtu Zhongguo, Shanghai: Shanghai Guanchashe).

Feldman, M., Francis, J., Bercovitz, J. (2005) Creating a cluster while building a firm: entrepreneurs and the formation of industrial clusters, Regional Studies, 39: 129141.

Freedman, M. (1961) The family in China, past and present, Pacific Affairs, 34: 323-336.

Frenken, K., van Oort, F.G., Verburg, T. (2007) Related variety, unrelated variety and regional economic growth, Regional Studies, 41: 685-697.

Gertler, M. (2004) Manufacturing Culture: The Institutional Geography of Industrial Practice, Oxford: Oxford University Press.

Giddens, A. (1984) The Constitution of Society: Outline of the Theory of Structuration, Cambridge: Polity.

Giddens, A. (1990) The Consequence of Modernity, Stanford: Stanford University Press.

Grabher, G. (1993) The weakness of strong ties: the "lock-in" of regional development in the Ruhr area, in G. Grabher (ed.) The Embedded Firm: On the Socio-Economics of Industrial Networks, pp. 255-278. London: Routledge.

Granovetter, M. (1973) The strength of weak ties, American J ournal of Sociology, 78: 1360-1380. 
Granovetter, M. (1985) Economic action and social structure: the problem of embeddedness, American J ournal of Sociology, 91: 481-510.

Gregory, D. (1989) Presences and absences: time-space relations and structuration theory, in D. Held and J.B. Thompson(eds.) Social Theory of Modern Societies: Anthony Giddens and His Critics, pp. 185-214. Cambridge: Cambridge University Press.

Gulati, R., Higgins, M.C. (2003) Which ties matter when? The contingent effects of interorganizational partnerships on IPO success, Strategic Management J ournal, 24: $127-144$.

Guthrie, D. (1998) The declining significance of Guanxi in China's economic transition, The China Quarterly, 154: 254-282.

Hadjimichalis, C. (2006) The end of Third Italy as we knew it? Antipode, 38: 82-106.

Hayter, R. (2004) Economic geography as dissenting institutionalism: the embeddedness, evolution and differentiation of regions, Geografiska Annaler, 86 B: $95-115$.

Henn, S. (2006) Regional Nanotechnology Clusters: Genesis, Characteristics, Policy Implications, Frankfurt/Main: Peter Lang (in German).

Henn, S., Laureys, E. (2010) Bridging ruptures: the re-emergence of the Antwerp diamond district after World War II and the role of strategic action, in D. Fornahl, S. Henn and M.-P. Menzel (eds), Emerging Clusters: Theoretical, Empirical and Political Perspectives in the Initial Stage of Cluster Evolution, pp. 74-96. Cheltenham: Edward Elgar.

Hsu, J.-Y., Saxenian, A. (2000) The limits of Guanxi capitalism: transnational collaboration between Taiwan and the USA, Environment and Planning A, 32: 1991-2005. 
Humphrey, J. (1995) Industrial reorganization in developing countries: from models to trajectories, World Development, 23: 149-162.

Iammarino, S., McCann, P. (2006) The structure and evolution of industrial clusters: transactions, technology and knowledge spillovers, Research Policy, 35: 10181036.

Klepper, S. (1997) Industry life cycles, Industrial and Corporate Change, 6: 145-181.

Kenney, M., von Burg, U. (1999) Technology, entrepreneurship and path dependence: industrial clustering in Silicon Valley and Route 128, Industrial and Corporate Change, 8: 67-103.

Krugman, P. (1993) First nature, second nature and metropolitan location, J ournal of Regional Science, 33: 120-144.

Li, Z.-Z. (1989) Strictly control the production of aluminium windows and doors, The Economic Daily, 10 January, 2 (in Chinese).

MacKinnon, D., Cumbers, A., Pike, A., Birch, K., McMaster, R. (2010) Evolution in economic geography: institutions, political economy, and adaptation, Economic Geography, 85: 129-150.

Malmberg, A., Maskell, P. (2002) The elusive concept of localization economies: towards a knowledge-based theory of spatial clustering, Environment and Planning A, 34: 429-449.

Markusen, A. (1996) Sticky places in slippery space: a typology of industrial districts, Economic Geography, 72: 293-313.

Martin, R., Sunley, P. (2006) Path dependence and regional economic evolution, J ournal of Economic Geography, 6: 395-437.

Martin, R. (2010) Rethinking regional path dependence: beyond lock-in to evolution, Economic Geography, 86: 1-27. 
Maskell, P., Malmberg, A. (2007) Myopia, knowledge development and cluster evolution, J ournal of Economic Geography, 7: 603-618.

Menzel, M.-P., Fornahl, D. (2009) Cluster life cycles - dimensions and rationales of cluster evolution, Industrial and Corporate Change, 19: 205-238.

Merton, R. (1936) The unanticipated consequences of purposive social action, American Sociological Review, 6: 894-904.

Meyer, D. (1998) Formation of advanced technology districts: New England textile machinery and firearms, 1790-1820. Economic Geography, 74: 31-45.

Miao, C.-H., Wei, Y.H.D., Ma. H. (2007) Technological learning and innovation in China in the context of globalization, Eurasian Geography and Economics, 48: 713-732.

Miles, M.B., Huberman, A.M. (1994) Qualitative Data Analysis: An Expanded Sourcebook, 2nd edn. Thousand Oaks, CA: Sage.

Nadvi, K. (1999) Shifting ties: social networks in the surgical instrument cluster of Sialkot, Pakistan, Development and Change, 30: 141-175.

Nohria, N. (1992) Introduction: is a network perspective a useful way of studying organizations, in N. Nohria and R.G. Eccles (eds), Networks and Organizations: Structure, Form, and Action, pp. 1-22. Cambridge: Harvard University Press.

Nooteboom, B. (2000) Learning and Innovation in Organizations and Economies, Oxford: Oxford University Press.

Owen-Smith, J., Powell, W.W. (2006) Accounting for emergence and novelty in Boston and Bay area biotechnology, in P. Braunerhjelm and M. Feldman (eds), Cluster Genesis: Technology-based Industrial Development, pp. 61-86. Oxford: Oxford University Press.

Penrose, E.T. (1952) Biological analogies in the theory of the firm. American Economic Review, 42: 804-819.

Piore, M.J., Sabel, C.F. (1984) The Second Industrial Divide, New York: Basic Books. 
Pouder, R., St. John, C. (1996) Hot spots and blinds spots: geographical clusters of firms and innovation, The Academy of Management Review, 21: 1192-1225.

Porter, M.E. (1990) The Competitive Advantage of Nations, New York: Free Press.

Rigby, D. L., Essletzbichler, J. (1997) Evolution, process variety, and regional trajectories of technological change in U.S. manufacturing, Economic Geography, 73: 269284 .

Rüttimann, B.G. (2004) The effects of globalization on the aluminium extrusion industry, Paper presented at the 8th International Aluminium Extrusion Technology Seminar, Orlando, 18-21 May. URL: http://www.brunoruettimann.de/orlando.html, accessed 15 October 2010.

Sammarra, A., Belussi, F. (2006) Evolution and relocation in fashion-led Italian districts: evidence from two case studies, Entrepreneurship \& Regional Development, 18: $543-562$.

Saxenian, A. (1994) Regional Advantage: Culture and Competition in Silicon Valley and Route 128, Cambridge: Harvard University Press.

Saxenian, A. (1999) Comment on Kenney and von Burg, "Technology, entrepreneurship and path dependence: industrial clustering in Silicon Valley and Route 128”, Industrial and Corporate Change, 8: 105-110.

Saxenian, A. (2006) The New Argonauts: Regional Advantage in a Global Economy, Cambridge: Harvard University Press.

Saxenian, A., Hsu, J.-Y. (2001) The Silicon Valley-Hsinchu connection: technical communities and industrial upgrading, Industrial and Corporate Change, 10: 893-920.

Scott, A.J. (2006) Origins and growth of the Hollywood motion-picture industry: the first three decades, in P. Braunerhjelm and M. Feldman (eds). Cluster Genesis: 
Technology-Based Industrial Development. pp. 17-38. Oxford: Oxford University Press.

Scott, A.J., Pope, N.E. (2007) Hollywood, Vancouver, and the world: employment relocation and the emergence of satellite production centers in the motionpicture industry, Environment and Planning A, 39: 1364-1381.

Silverman, D. (2001) Interpreting Qualitative Data: Methods for Analysing Talk, Text and Interaction, 2nd edn. London: Sage.

Song, H.-G. (1993) Teahouses in Dali, The Economic Daily, 26 March: 2 (in Chinese).

Staber, U. (1997) An ecological perspective on entrepreneurship in industrial districts, Entrepreneurship and Regional Development, 9: 45-64.

Storper, M. (2004) Society, community and economic development, in H. Gebhardt, P. Meusburger, P. (eds). Hettner-Lecture 2003 with Michael Storper Institutions, Incentives and Communication in Economic Geography'. pp. 7-39. Stuttgart: Steiner.

Storper, M. (2009a) The economics of context, location and trade: another great transformation? In G. Becattini, M. Bellandi, L. De Propris (eds). The Handbook of Industrial Districts. pp. 141-157. Cheltenham: Edward Elgar.

Storper, M. (2009b) Regional context and global trade, Economic Geography, 85: 1-21.

Storper, M., Salais, R. (1997) Worlds of Production: The Action Framework of the Economy, Cambridge, MA: Harvard University Press.

Storper, M., Walker, R. (1989) The Capitalist Imperative: Territory, Technology and Industrial Growth, Cambridge: Blackwell.

Stuckey, J.A. (1983) Vertical Integration and J oint Ventures in the Aluminium Industry, Cambridge, MA: Harvard University Press.

Swan, P. (2002) Towards a model of clustering in high-technology industries, in P. Swann, M. Prevezer and D. Stout (eds). The Dynamics of Industrial Clustering: 
International Comparisons in Computing and Biotechnology. pp. 52-76. Oxford: Oxford University Press.

Sydow, J., Lerch, F., Staber, U. (2010) Planning for path dependence? The case of a network in the Berlin-Brandenburg optics cluster, Economic Geography, 86: 173195.

Ter Wal, A.L.J., Boschma, R.A. (2009) Co-evolution of firms, industries and networks in space, Regional Studies, 45: in press.

Tonkin, E. (1992) Narrating Our Pasts: the Social Construction of Oral History, Cambridge: Cambridge University Press.

Turner, S. (2010) Networks of learning within the English wine industry, J ournal of Economic Geography, 10: 685-715.

Vernon, R. (1966) International investment and international trade in the product cycle, The Quarterly J ournal of Economics, 80: 190-207.

Yeung, H.W.-C., Lin, G.C. (2003) Theorizing economic geographies of Asia, Economic Geography, 79: 107-128.

Wang, J. (2001) Innovative Space: Enterprise Clusters and Regional Development, Beijing: Peking University Press (in Chinese).

Wang, J. (2010) Beyond Clusters: Theoretical Exploration of Industrial Clusters in China, Beijing: Science Press (in Chinese).

Wei, D.Y.-H., Li, W., Wang, C. (2007) Restructuring industrial districts, scaling up regional development: a study of the Wenzhou model, China, Economic Geography, 83: 421-444.

Whitford, J. (2001) The decline of a model? Challenge and response in the Italian industrial districts, Economy and Society, 30: 38-65.

Williamson, O. (1985) The Economic Institutions of Capitalism, New York: Free Press. 
Xiang, B. (2005) Transcending Boundaries, transl. by J. Weldon. Leiden: Brill Academic Publishers.

Yamamura, E., Sonobe, T., Otsuka, K. (2003) Human capital, cluster formation, and international relocation: the case of the garment industry in Japan, 1968-98, J ournal of Economic Geography, 3: 37-56. 
Figure 1: A tri-polar analytical framework of cluster evolution

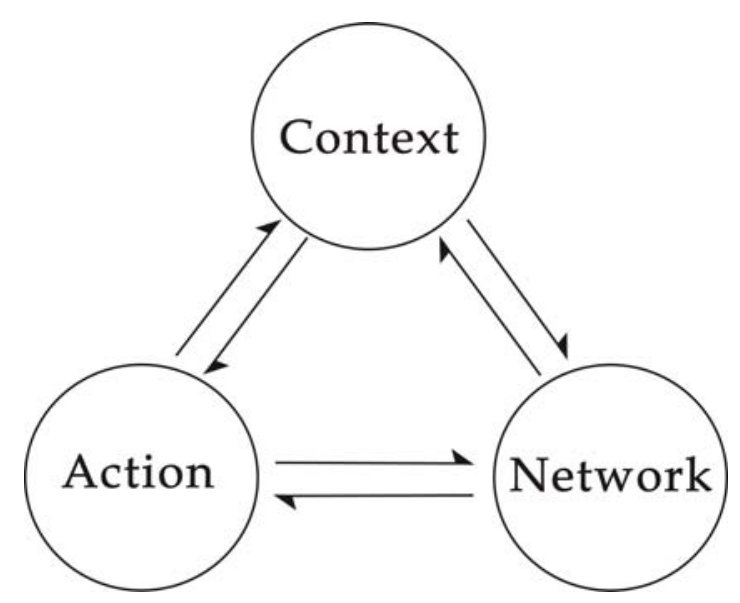




\section{Figure 2: Spatial distribution of the aluminium extrusion industry in}

\section{Dali, China, 2009}

Source: Developed from data provided by the Guangdong Technical Innovation Centre for Nonferrous Metal Industries.

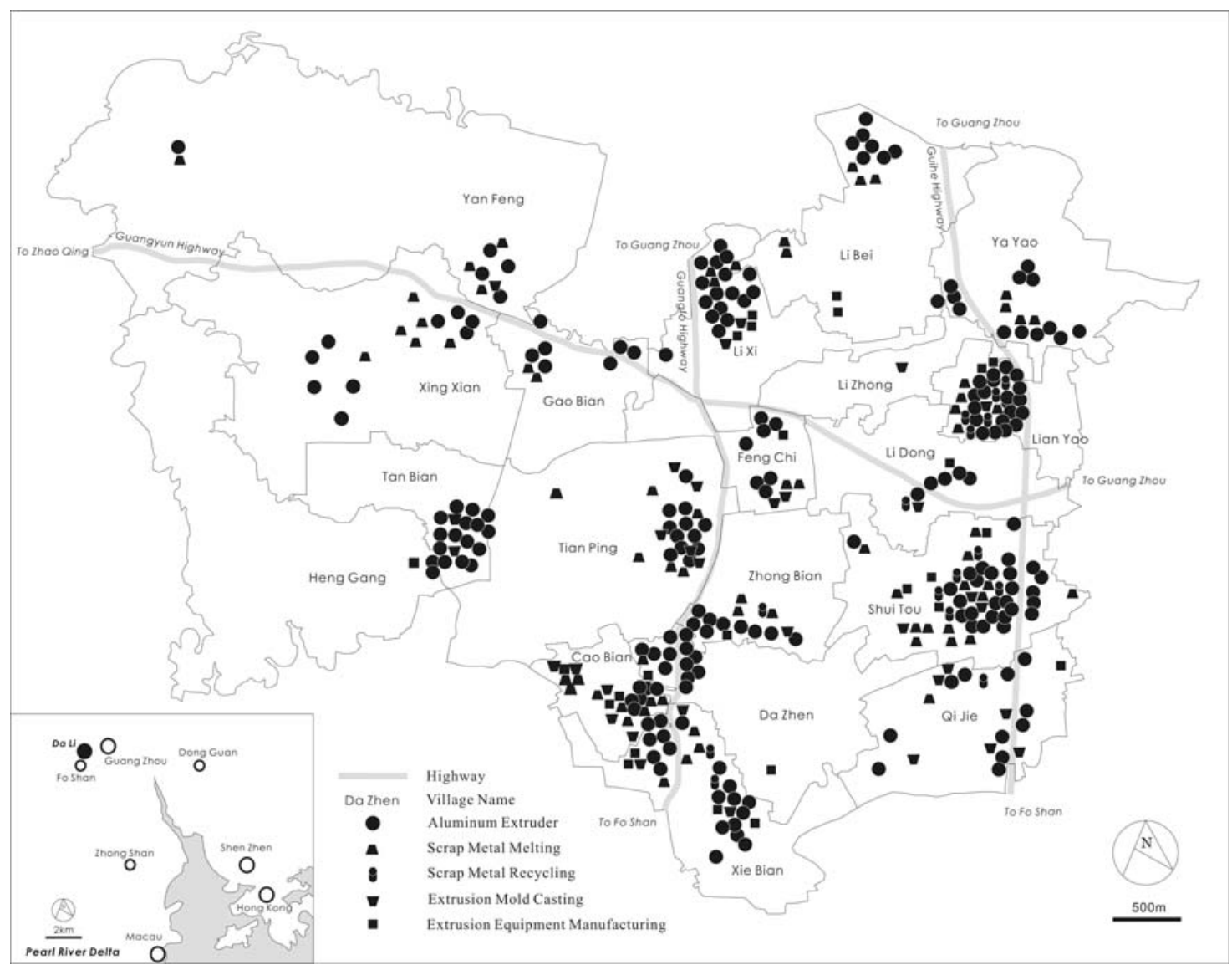

Note: The total number of aluminium extruders according to this database is nearly 200. In 2006, the national government set up an aluminium extrusion permit system to improve product quality. Since then, aluminium extruders are required to apply for a permit. The 100 firms mentioned in the main text refer to the legitimate aluminium extruders in Dali, while the map also shows another nearly 100 small "illegal" extruders. 
Figure 3. Number of enterprises and employment in the aluminium industry in Dali, China, 1990 - 2002

Source: Committee of Dali Chronicles (2008)

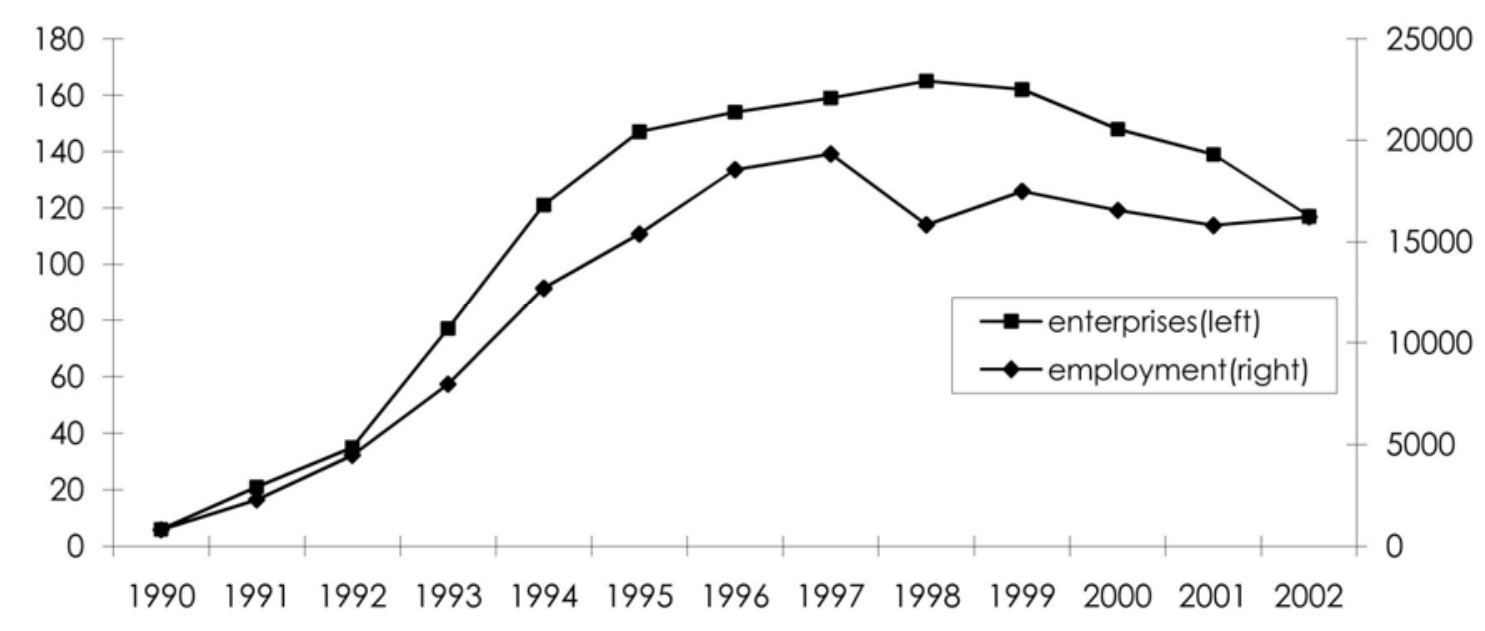

